Original Research Article

\title{
A questionnaire based study on the knowledge, attitude, practice of staff nurses about pharmacovigilance in a tertiary care hospital
}

\author{
Prema M.*, Nalini G. K., Sahana G. N., Deepak P., Jayashree V. Nagaral, \\ Geeta Rathod, Nuthan Kumar U. S.
}

Department of Pharmacology, Hassan Institute of Medical Sciences, Hassan, Karnataka, India

Received: 06 May 2017

Accepted: 31 May 2017

*Correspondence to:

Dr. Prema M.,

Email: premimuthusamy@ gmail.com

Copyright: (C) the author(s), publisher and licensee Medip Academy. This is an openaccess article distributed under the terms of the Creative Commons Attribution NonCommercial License, which permits unrestricted noncommercial use, distribution, and reproduction in any medium, provided the original work is properly cited.

\begin{abstract}
Background: Adverse drug reactions (ADR) - one of the global problems of major concern leading to morbidity and mortality. Spontaneous reporting of ADR is the cornerstone of Pharmacovigilance (PV) programme and it is important to reduce the risk of drug related harm to the patient. The active participation of healthcare professionals (Doctors, Nurses, Pharmacist) play a major role in the success of Pharmacovigilance. The objective of the study was to assess the knowledge, attitude, practice of Staff Nurses about Pharmacovigilance in a tertiary care hospital.

Methods: A Cross sectional, Observational questionnaire based study was carried out using a pre designed KAP questionnaire. Study included 100 staff nurses who were working in Hassan institute of medical sciences (HIMS). The results were analyzed using descriptive statistics

Results: In our study $65 \%$ participants knows the correct definition and $48.8 \%$ knows the important purpose of Pharmacovigilance and $77.5 \%$ aware of existence of ADR reporting system in India. There was huge gap between ADR experienced $(53.8 \%)$ and ADR reported $(21.3 \%)$. The determinants of under reporting from our study include Lack of time / overburdened (33.7\%) and lack of knowledge about ADR (31.25\%).

Conclusions: This study showed that majority of participants understand the need for reporting of ADR. In spite of that the reporting rate of ADRs by them is very low. Hence, there is a need to create awareness about the importance of reporting ADR by conducting many Pharmacovigilance programme.
\end{abstract}

Keywords: Adverse drug reaction, Pharmacovigilance, Staff nurses

\section{INTRODUCTION}

Drugs are the most common medical interventions, primarily used to relieve sufferings. But it has been recognized long ago that drug themselves can prove fatal; as the saying rightly goes "Drugs are Double Edged Weapons". 1

Adverse drug reactions are one of the major reasons of morbidity and mortality all over the world and hence proper monitoring of ADRs is mandatory. ${ }^{2}$
As per World Health Organization, Adverse drug reactions (ADR) is any noxious, unintended and undesired effect of the drug which occurs at doses used in humans for the prophylaxis, diagnosis or therapy of a disease or the modification of physiological state.,

Studies have shown that ADRs are an important cause of hospital admissions. ${ }^{4-7}$

The incidence of serious ADRs is $6.7 \%$ in India and reporting of serious ADRs rarely exceeds $10 \% .^{8-10}$ 
Pharmacovigilance is defined as science and activities related to detection, assessment, understanding and prevention of adverse drug reactions or any drug related problem. $^{4,11}$ Spontaneous reporting of ADRs is the important part of pharmacovigilance and is mainly to maintain the patient safety.

In India, all healthcare professionals including doctors, nurses, and pharmacists can report an ADR by filling an ADR form of the Central Drugs Standard Control Organization (CDSCO) and the active participation of these people can improve the ADR reporting. ${ }^{2,12}$ There are so many studies conducted about Pharmacovigilance among doctors. ${ }^{13-17}$ Even though Doctors are the one who are prescribing drugs, it is the Nurses who are close to the patient and administering drugs, monitor them continuously, known to have an important role in ADR reporting and constitute a potentially valuable source for spontaneous ADR reports in hospitals. ${ }^{18}$ Thus, the knowledge and attitudes of hospital nurses on spontaneous reporting of ADRs and difficulties in reporting and the ways to solve them are very important. This study was conducted to assess the knowledge, attitude and practice (KAP) of staff nurses in our hospital (Hassan Institute of Medical Sciences).

\section{METHODS}

This study was conducted at Hassan Institute of Medical Sciences, a tertiary care Hospital in Hassan, Karnataka, India. The duration of the study was one month, July 2015.

A cross-sectional questionnaire-based study conducted after getting informed consent from 100 staff nurses, who were working at the hospital during the study period.

KAP questionnaire was designed to assess, their knowledge of pharmacovigilance, attitudes towards pharmacovigilance, and their practice on ADR reporting. There were 16 questions of which seven related to knowledge, four related to attitude, and four related to practice. One question was asked to determine the reasons for under reporting.

\section{Statistical analysis}

Descriptive statistics was applied to infer the findings.

\section{RESULTS}

\section{Knowledge related questions}

Nurses knowledge towards the ADR reporting was evaluated using 6 pharmacovigilance related questions.

$65 \%$ staff nurses gave correct response regarding the definition of pharmacovigilance and $48.8 \%$ know the important purpose of Pharmacovigilance and $77.5 \%$ aware of existence of ADR reporting system in India.
47.5\% were aware that the regulatory body responsible for monitoring ADRs in India is Central Drugs Standard Control Organization (CDSCO). Only $32.5 \%$ were aware that International Center for ADR monitoring is located in Sweden. Unfortunately, only $33.75 \%$ healthcare professional were aware that a serious adverse event should be reported to the regulatory authority within 14 calendar days (Table 1).

Table 1: Knowledge related questions.

\begin{tabular}{|c|c|c|}
\hline Questions & $\begin{array}{l}\text { Correct } \\
\text { response }(\%)\end{array}$ & $\begin{array}{l}\text { Incorrect } \\
\text { response }(\%)\end{array}$ \\
\hline $\begin{array}{l}\text { 1. Pharmacovigilance } \\
\text { is defined as }\end{array}$ & 65 & 35 \\
\hline $\begin{array}{l}\text { 2. The important } \\
\text { purpose of } \\
\text { Pharmacovigilance } \\
\text { is }\end{array}$ & 48.75 & 51.25 \\
\hline $\begin{array}{l}\text { 3. Are you aware of } \\
\text { existence of ADR } \\
\text { reporting system } \\
\text { in India? }\end{array}$ & 77.5 & 22.5 \\
\hline $\begin{array}{l}\text { 4. Which regulatory } \\
\text { body is } \\
\text { responsible for } \\
\text { monitoring ADRs } \\
\text { in India? }\end{array}$ & 47.5 & 52.5 \\
\hline $\begin{array}{l}\text { 5. Where are the } \\
\text { International } \\
\text { centre for ADR } \\
\text { monitoring is } \\
\text { located? }\end{array}$ & 32.5 & 67.5 \\
\hline $\begin{array}{l}\text { 6. A serious adverse } \\
\text { event should be } \\
\text { reported to } \\
\text { regulatory body } \\
\text { within }\end{array}$ & 33.75 & 66.25 \\
\hline
\end{tabular}

\section{Attitude related questions}

To explore nurses attitudes towards pharmacovigilance, 4 questions were designed.

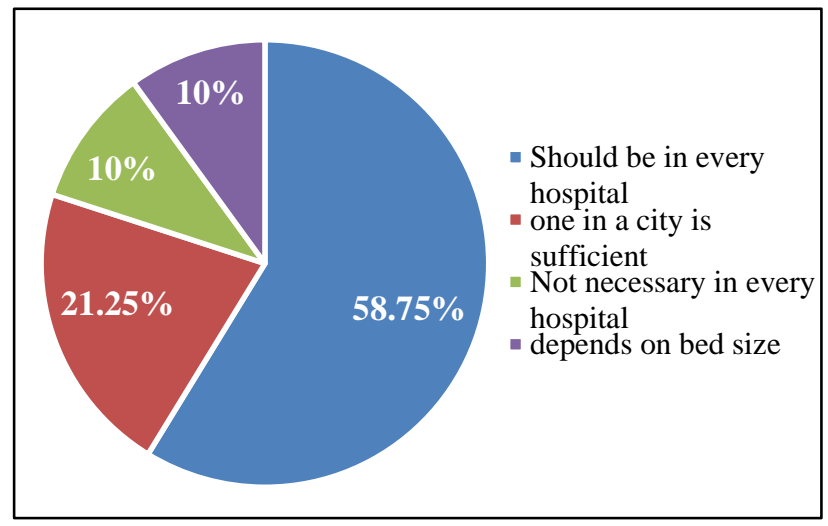

Figure 1: Opinion about establishing ADR monitoring centre. 
$58.75 \%$ agreed that ADR monitoring center should be established in every hospital and $60 \%$ chose phone as the preferred mode to inform about ADR (Figure 1 and Figure 2).

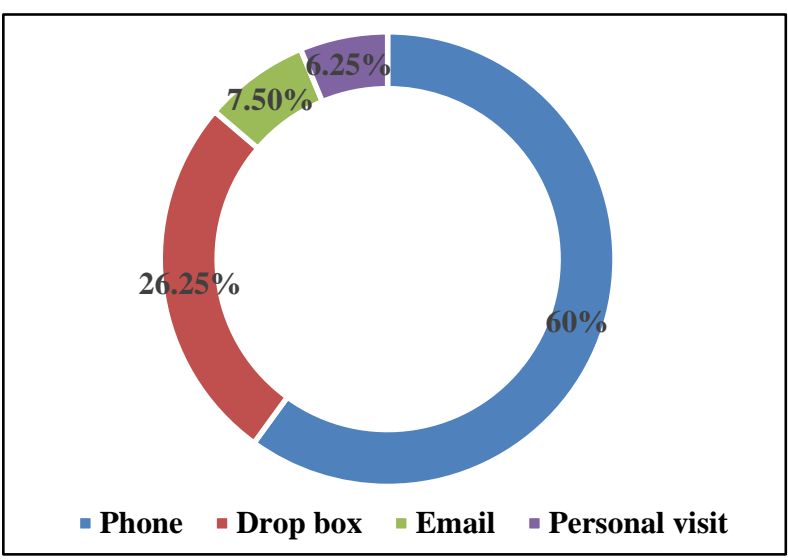

Figure 2: Different methods of reporting ADRs by nurses.

$58.75 \%$ mentioned that ALL ADRs should be reported. $27.5 \%$ mentioned only SERIOUS ADRs should be reported. $50 \%$ of Staff nurses mentioned that ADR reporting doesn't damage professional image.

The factors discouraging participants from reporting ADRs were lack of time to report ADR (33.75\%) and lack of knowledge about ADR (31.25\%) (Figure 3).

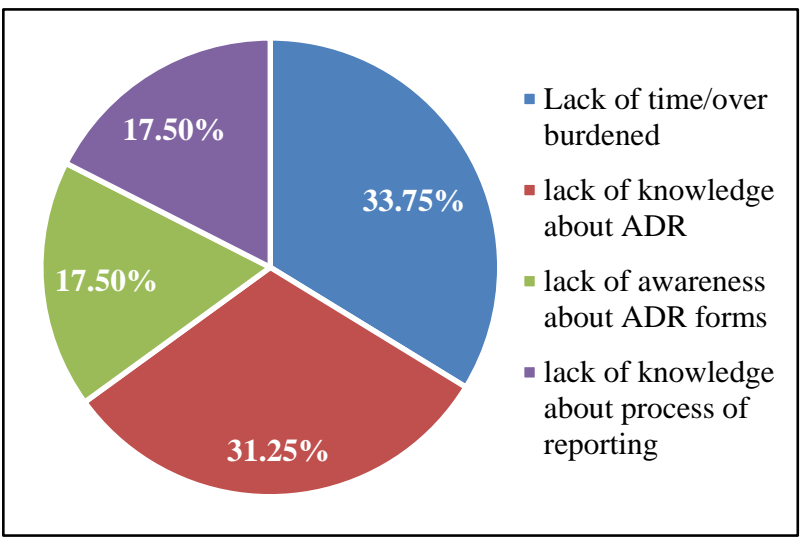

Figure 3: Factors discouraging reporting of ADR.

\section{Practice related questions}

Majority of the participants, 69 out of $80(86.3 \%)$ accepted that reporting of ADR is necessary and 53 out of $80(66.3 \%)$ were taught about ADR reporting.

The interesting fact here is $53.6 \%$ have come across ADR but only $21.3 \%$ reported ADR which shows the unawareness of nurses about the importance of ADR reporting (Figure 4).

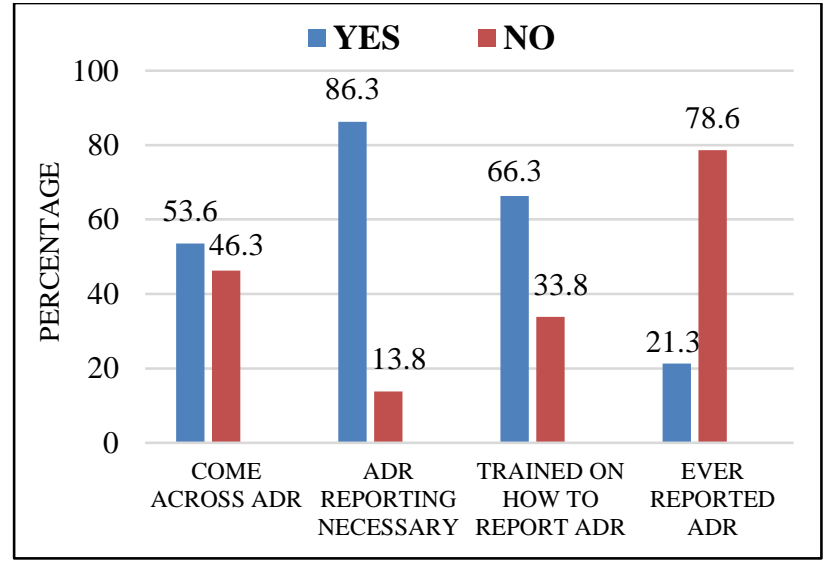

Figure 4: Practice related questions.

\section{DISCUSSION}

Hospital nurses could play an important role in ADRs reporting, because they are close to the patient and have good knowledge of health criteria, symptoms, drugs and ADRs. Given their unique position in drug administration and recording side effects, nurses are well-placed to monitor the patients' response to drugs. They are often the source in alerting the responsible physician about possible ADRs. There is thus a logical reason to involve nurses and encourage them to contribute in ADR reporting system. ${ }^{18}$

According to the results of our study $65 \%$ knows the correct definition of Pharmacovigilance and $48.75 \%$ knows the importance of Pharmacovigilance whereas in other study conducted by Hanafi S et al, only $32 \%$ knows the correct definition of ADR. ${ }^{18}$

$77.5 \%$ aware of existence of ADR reporting system in India. A study conducted by Rajesh $\mathrm{R}$ et al, showed that $68 \%$ are aware of existence of ADR reporting system. ${ }^{19}$

47.5\% knew that in India the Central Drugs Standard Control Organization (CDSCO) is a regulatory body responsible for monitoring ADRs which is high compared to study conducted by Arjun $\mathrm{T} \mathrm{N}$ et al, where only few i.e. $28.57 \%$ gave correct response. ${ }^{12}$

The above findings showed that nurses in our college has better knowledge about pharmacovigilance and this might be due to the frequent pharmacovigilance awareness programme conducted by our institution.

Most of the staff nurses (86.3\%) accepted that reporting ADR is necessary and pharmacovigilance should be taught in detail to healthcare professionals. These findings are in correlation with findings of a study conducted by Arjun T N et al. ${ }^{12}$

In our study there was huge gap between ADR experienced $(53.8 \%)$ and ADR reported $(21.3 \%)$ in spite of people trained on how to report an ADR (66.3\%) 
similar to a study conducted by Gupta SK et al, showed that gap between ADR experienced (64.4\%) and reported $(22 \%)^{2}$

Most of them in our study were not aware of what kind of ADR to be reported. $58.75 \%$ mentioned that ALL ADRs should be reported. $27.5 \%$ mentioned only SERIOUS ADRs should be reported.

Lack of time/ overburdened (33.7\%) and lack of knowledge about ADR (31.25\%) were the major determinants of under reporting from our study which is similar to the studies conducted by Amancharla MK et $\mathrm{al}^{4}$

These findings suggest the need for interventions to improve the KAP of the nurses.

\section{CONCLUSION}

This study showed that majority of the participants had good knowledge and attitude about pharmacovigilance and understand the need for reporting. In spite of that the reporting rate of ADRs by them is very low. Hence, there was huge gap between the ADR experienced and ADR reported. The fact that majority of respondents agreed that reporting of ADR is necessary and awareness that pharmacovigilance should be taught in detail to healthcare professionals emphasize that they have started to understand the importance of pharmacovigilance.

\section{ACKNOWLEDGMENTS}

Authors would like to thank all the professors, post graduates of Department of Pharmacology and staff nurses of Sri Chamarajendra Hospital, Hassan Institute of Medical Sciences, Hassan.

\section{Funding: No funding sources}

Conflict of interest: None declared

Ethical approval: The study was approved by the Institutional Ethics Committee of Hassan Institute of Medical Sciences (HIMS), Hassan

\section{REFERENCES}

1. Shamna M, Dilip C, Ajmal M, Mohan PL, Shinu C, Jafer CP, et al. A prospective study on Adverse Drug Reactions of antibiotics in a tertiary care hospital. Saudi Pha J. 2014;22:303-8.

2. Gupta SK, Nayak RP, Shivaranjani R, Vidyarthi SK. A questionnaire study on the knowledge, attitude, practice of Pharmacovigilance among the healthcare professionals in a teaching hospital. 2015;6(1):45-52.

3. The world health organization: A safety of medicines a guide to detecting and reporting adverse drug reactions, Geneva, 2002.

4. Amancharla MK, Choppara JV, Keelu RK, Kommavarapu P, Kotannagari VV. Study of Awareness of Pharmacovigilance among healthcare professionals in a tertiary care hospital in Andhrapradesh. IJCMAAS. Jan 2015;5(2):63-7.

5. Lazarou J, Pomeranz BH, Corey PN. Incidence of adverse drug reactions in hospitalized patients: a meta-analysis of prospective studies. JAMA. 1998 Apr 15;279(15):1200-5.

6. Ramesh M, Pandit J, Parthasarathi G. Adverse drug reactions in a south Indian hospital-their severity and cost involved. Pharmacoepidemiol Drug Saf. 2003;12:687-92.

7. Arulmani R, Rajendran SD, Suresh B. Adverse drug reaction monitoring in a secondary care hospital in South India. Br J Clin Pharmacol. 2007;65:210-6.

8. Importance of ADR reporting in India. [Last cited on 2011 Mar 15]. Available at: http://www.pharmacovigilance.co.in/whyadrreporting .html

9. Desai CK, Iyer G, Panchal J, Shah S, Dikshit RK. An evaluation of knowledge, attitude, and practice of adverse drug reaction reporting among prescribers at a tertiary care hospital. Perspectives in Clinical research. 2011 Oct-Dec;2(4):129-36.

10. Green CF, Mottram DR, Rowe PH, Pirmohamed M. Attitudes and knowledge of hospital pharmacists to adverse drug reaction reporting. Br J Clin Pharmacol. 2001 Jan 1;51(1):81-6.

11. Arbind KC, Nivedhitha $\mathrm{S}$, Manicvasagam S, Tirumalikolundu SP. Awareness and perception experiences on adverse drug reaction among doctors, nurses and pharmacists of a tertiary care rural teaching hospital.Indian J Drugs Dis. 2013;2:248-58.

12. Arjun TN, Sudhir H, Gouraha A, Jain S, Chavan K, Dayma A. Assessment of knowledge, attitude and practice related to pharmacovigilance among the healthcare professionals in a teaching hospital in central india: A questionnaire study. World J Pharm Pharm Sci. 2015 Jan 17;4:785-99.

13. Gupta P, Udupa A. Adverse drug reaction reporting and pharmacovigilance: Knowledge, attitudes and perceptions amongst resident doctors. J Pharm Sci Res. 2011;3(2):1064-9.

14. Ramesh M, Parthasarathi G. Adverse drug reactions reporting: attitudes and perceptions of medical practitioners. Asian J Pharm Clin Res. 2009 Apr;2(2):10-4.

15. Palanisamy S, Kumaran AKS, Rajasekaran A. A study on assessment, monitoring, documentation and reporting of adverse drug reactions at a multispecialty tertiary care teaching hospital in South India. Int J Pharm Tech Res. 2009;4:1519-22.

16. Amirta P, Singh SP. Status of spontaneous reporting of adverse drug reaction by physicians in Delhi, Indian J. Pharmacy practice. 2011;4(2):29-36.

17. Rehan HS, Vasudev K, Tripathi CD. Adverse drug reaction monitoring: knowledge, attitude and practices of medical students and prescribers. National Medical Journal of India. 2002 Jan 1;15(1):24-6.

18. Hanafi S, Torkamandi H, Hayatshahi A, Gholami K, Javadi M. Knowledge, attitudes and practice of 
nurses regarding adverse drug reaction reporting. Iranian journal of nursing and midwifery research. 2012 May 1;17(1):21-5.

19. Rajesh R, Vidyasagar S, Varma DM. An Educational Intervention to assess Knowledge Attitude Practice of pharmacovigilance among Health care professionals in an Indian tertiary care teaching hospital. Int $\mathbf{J}$ Pharm Tech Res. 2011 Apr;3(2):678-92.

Cite this article as: Prema M, Nalini GK, Sahana GN, Deepak P, Nagaral JV, Rathod G, et al. A questionnaire based study on the knowledge, attitude, practice of staff nurses about pharmacovigilance in a tertiary care hospital. Int J Basic Clin Pharmacol 2017;6:1758-62. 